\title{
Financial burden of orthopaedic gunshot-related injury management at a major trauma centre
}

\author{
M van Heukelum, MB ChB, DA (SA); N le Roux, MB ChB; S Jakoet, MB ChB; N Ferreira, BSc, MB ChB, FC Orth (SA), MMed (Orth), PhD \\ Division of Orthopaedic Surgery, Department of Surgical Sciences, Faculty of Medicine and Health Sciences, Stellenbosch University, Cape Town, \\ South Africa
}

Corresponding author: $M$ van Heukelum (marcusvanh@gmx.com)

Background. Violence and injuries are a significant global public health concern, and have a substantial emotional, physical and economic impact on society. In South Africa (SA), the Western Cape Injury Mortality Profile shows that homicides increased from 38 deaths per 100000 in 2010 to 52 deaths per 100000 in 2016. This increase is directly related to an increase in firearm-related homicides, which doubled from 2010 to 2016. Previous research estimated the average cost per gunshot wound (GSW)-related orthopaedic patient at USD2 940. GSWrelated patient numbers as well as treatment costs have escalated exponentially over the past few years.

Objectives. To calculate the financial costs involved in managing gunshot-related orthopaedic injuries both surgically and non-surgically at a tertiary centre in SA.

Methods. After ethics approval, a retrospective review of all GSW patients seen in the emergency unit at Tygerberg Hospital in 2017 was undertaken. Patient records yielded data on the following parameters: injury site and characteristics, imaging modalities, orthopaedic management, hospital admission and duration of hospitalisation, theatre episodes, orthopaedic implants and blood products administered. Cost analysis was performed using this information.

Results. A total of 389 patients ( 360 male and 29 female), average age (range, standard deviation) $28(3-69,9.50)$ years, were treated during the study period. Patient records identified a total of 449 orthopaedic injuries. A total of 187 patients were admitted, with 175 requiring surgical fixation. The conservatively calculated cost of managing this patient group was ZAR10 227503 . The average management cost per patient was ZAR26 292, with an average of ZAR46 670 per case requiring surgical management and ZAR8 810 for non-surgical cases (the average USD-ZAR exchange rate in 2017 was USD1-ZAR13.30).

Conclusions. The total cost of managing 389 patients with gunshot-related orthopaedic injuries at a tertiary hospital was ZAR10 227503. Improved understanding of these costs will help the healthcare system better prioritise orthopaedic trauma funding and training and highlights the urgent need for cost-saving measures, specifically primary prevention initiatives.

S Afr Med J 2020;110(9):882-886. https://doi.org/10.7196/SAMJ.2020.v110i9.14638

Violence and injuries are a significant global public health concern and have a substantial emotional, physical and economic impact on society. ${ }^{[1]}$ Cape Town is one of the most violent cities in the world, with homicide rates comparable to those of countries at war. ${ }^{[2]}$

Mortality profiles show that homicide increased from 38 deaths per 100000 in 2010 to 52 deaths per 100000 in 2016. The increased homicide rate was due to an increase in firearm-related homicides, which doubled between 2010 and 2016. ${ }^{[3]}$ This year-on-year increase has continued and even peaked since 2016, resulting in the South African National Defence Force being deployed to the Cape Flats in July 2019.

In recent years, a high rate of interpersonal violence combined with gun trafficking and use of guns as the main weapon in gang wars has caused a surge of gun-related injuries in Western Cape Province. ${ }^{[4]}$ While the mortality rate attributable to firearms in SA is often quoted, the burden of non-fatal firearm-related injuries is unknown, and the SA government has not released disaggregated statistics on violent crime involving firearms or gun-related injuries in over a decade. Additionally, SA lacks a public national injury surveillance system to track fatal and non-fatal firearm injuries, ${ }^{[5]}$ leaving researchers to estimate the numbers of non-fatal firearmrelated injuries seen by healthcare workers across the country. Estimates by Allard and Burch ${ }^{[6]}$ published in 2005 suggested that
127000 non-fatal gunshot wounds (GSWs) occurred per annum across the country, while Martin et al. ${ }^{[5]}$ estimated that in 2012 SA had $>54870$ firearm-related injuries, at a rate of 105 GSWs per 100000 people. These estimates are outdated and probably underestimate the true number of cases.

Non-fatal firearm-related injuries add to the extreme trauma burden on the healthcare system in terms of time resources, healthcare workers and financial costs. Little is known of the true financial costs involved in managing these injuries, although it is accepted that orthopaedic GSWs are significantly more expensive to treat than non-orthopaedic GSWs. ${ }^{[5,6]}$ It was estimated in a 2005 study that managing abdominal GSWs costs $\sim$ USD1 467 per patient, ${ }^{[6]}$ while the average cost per GSW-related orthopaedic patient as calculated in 2012 was USD2 940. ${ }^{[5]}$ Apart from these studies, there is no other literature on the fiscal burden of treating gunshot-related orthopaedic trauma in the SA non-military setting.

\section{Objectives}

The primary objective of this study was to calculate the financial costs involved in managing gunshot-related orthopaedic injuries, both surgically and non-surgically, at a tertiary centre in SA and in doing so provide a costing model to determine the total financial impact of the current gunshot epidemic on the healthcare system. 


\section{Methods}

This retrospective study reviewed all gunshotrelated orthopaedic injuries presenting to a level I trauma centre in Cape Town between 1 January and 31 December 2017. Ethical approval from the Stellenbosch University Health Research Ethics Committee was obtained prior to commencement of the research (ref. no. N17/10/10).

Patients with gunshot-related orthopaedic injuries were identified by reviewing casualty trauma records for the given period. All patients who required orthopaedic consultation were included for review. Patients were excluded if records and documentation were incomplete.

Patient record review yielded data on the following parameters: injury site and characteristics, diagnostic imaging modalities, management received (operative and non-operative), hospital admission and duration of hospitalisation, theatre episodes, orthopaedic implants used and blood products administered (Table 1). Cost analysis pertaining to the included parameters was performed using the hospital Uniform Patient Fee Schedule (UPFS) of a level II patient and the 2017 hospital implant tender document.

Cost calculations for this study excluded consumables, laboratory investigations, medications administered, rehabilitation, transport, patient follow-up and complications.

\section{Results}

The study identified 389 patients with gunshot-related orthopaedic injuries treated during 2017. The study population consisted of 360 males and 29 females, with a mean (range, standard deviation) age of 28 (3 - 69, 9.50) years (Fig. 1).

The patient cohort sustained a total of 449 orthopaedic injuries, including 290 lower limb, 132 upper limb and 27 spinal injuries. The major anatomical locations of injuries were the femur $(n=85 ; 19 \%)$, tibia $(n=56$; $12 \%)$, pelvis $(n=45 ; 10 \%)$, forearm $(n=41$; $9 \%)$ and humerus ( $n=32 ; 7 \%)$. Sixty patients
(15.4\%) sustained multiple gunshot-related orthopaedic injuries, 53 (13.6\%) having two injuries and $7(1.8 \%)$ three or more injuries.

Of the 389 patients identified, 202 were treated non-operatively without requiring hospital admission; 187 required admission, with 175 requiring surgical management. Admitted patients' average duration of stay was 11 days, with the longest admission being 99 days. GSW-related orthopaedic admissions totalled 2060 days (79 intensive care and 1981 standard beds) at a cost of ZAR3 151608 (the average USD-ZAR exchange rate in 2017 was USD1-ZAR13.30).

A total of 1450 imaging investigations were performed, including 1214 radiographs, 167 computed tomography (CT) angiograms (39 upper limb and 128 lower limb) and 69 CT scans, costing a total of ZAR1 570 702. The most expensive individual imaging modality was CT angiograms, which totalled ZAR1 137270 (Fig. 2).

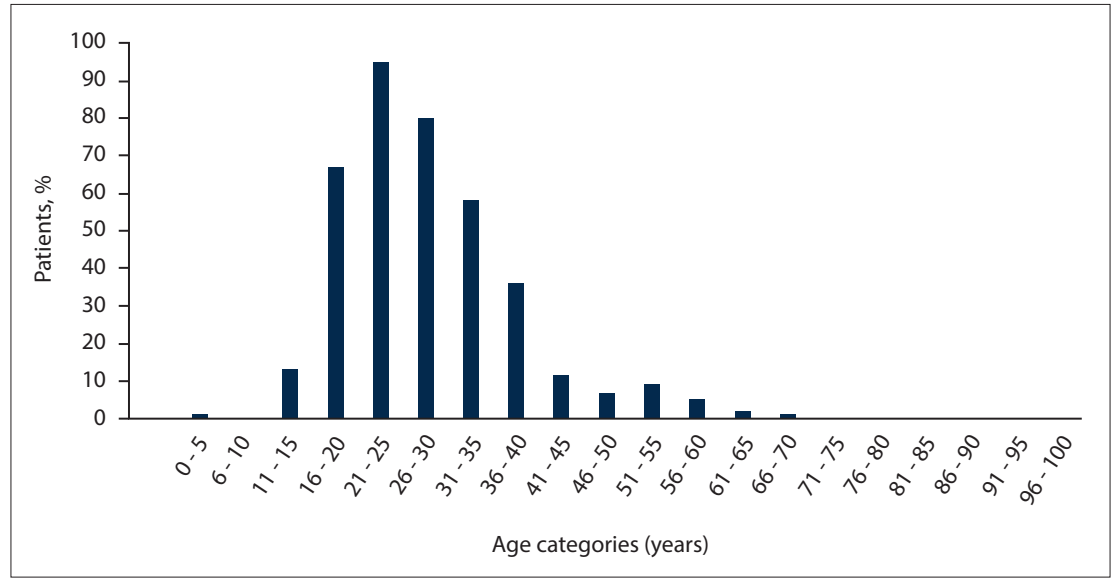

Fig. 1. Age breakdown of the study population.

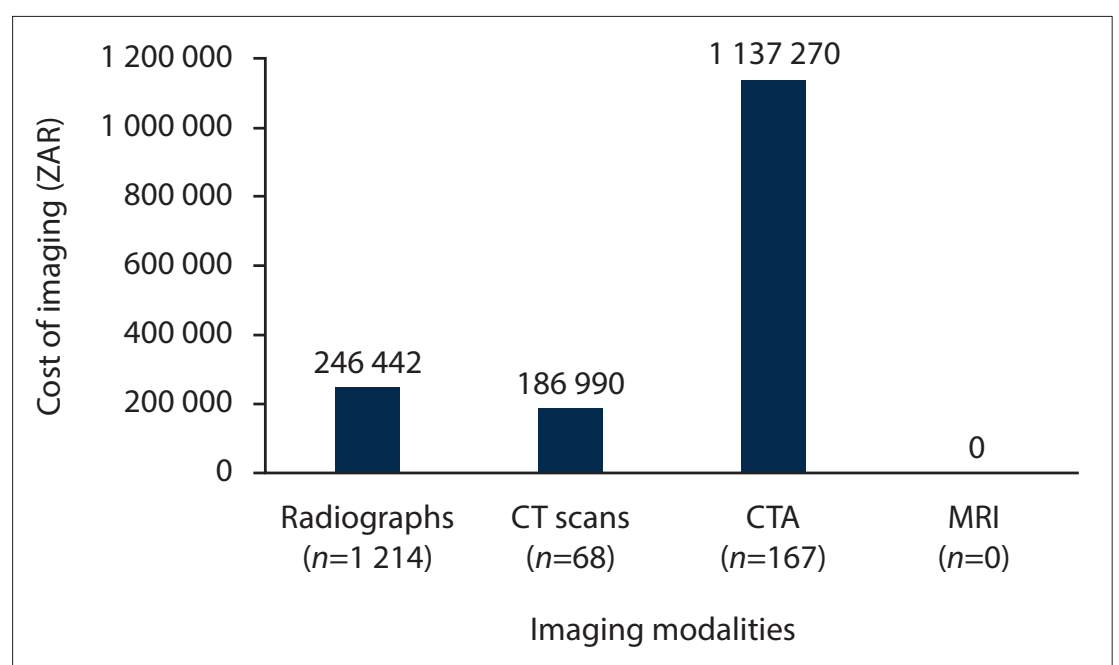

Fig. 2. Breakdown of imaging modalities and associated cost. $(C T=$ computed tomography; $C T A=$ computed tomography angiogram; $M R I=$ magnetic resonance imaging.)

\begin{tabular}{ll} 
Table 1. Parameters included in cost analysis & \\
\hline Emergency consultation & Facility fee, specialist medical practitioner, nursing practitioner \\
Imaging & Depending on modality (radiograph, MRI, CT scan, angiogram, etc.) \\
Inpatient admission & High care v. standard ward (calculated per 24 hours) \\
Theatre related & Depending on procedure \\
& Anaesthetic fee \\
& C-arm fluoroscopic imaging \\
Orthopaedic implant & As per provincial tender document \\
Blood products & As per Western Cape Blood Service \\
MRI = magnetic resonance imaging; $C T$ = computed tomography. &
\end{tabular}


Surgical treatment was required for 175 patients through 180 theatre episodes, with a total of 185 orthopaedic implants being used. Implant costs contributed ZAR2 333127 to the total cost, with theatre episodes adding an additional ZAR2 738 668. Most commonly used implants included 77 intramedullary nails (53 femur, 14 tibia and 10 humerus), 62 plate-and-screw constructs and 11 circular external fixators (Fig. 3).

Emergency consultation and casualty fees amounted to ZAR237 290, while blood products added an additional amount of ZAR196 108.

The total cost of care amounted to ZAR10 227503 (Fig. 4). The average cost per patient was ZAR26 292, with the most expensive patient costing ZAR280 124. Patients requiring surgical management cost an average of ZAR46 670 per case, with non-surgical patients costing ZAR8 810 on average (Fig. 5).

\section{Discussion}

Criminal activity causes more deaths globally than conflicts and terrorism combined. In 2017, the 464000 global victims of homicide surpassed the 89000 killed in armed conflicts and the 26000 fatal victims of terrorist violence. It is estimated that over the period 2000 - 2017, an average of 65000 killings per year were related to organised crime and gangs, and that up to $19 \%$ of all homicides recorded globally in 2017 were related to organised crime and gangs. ${ }^{[7]}$

The latest crime statistics for SA report an increased murder rate of $3.4 \%$ from 20336 cases in $2017 / 18$ to 21022 in $2018 / 19 .^{[8]}$ Firearms were the most commonly used weapon, although the percentages of deaths related to firearms were not specifically reported. Despite the burden of gunshot violence, SA lacks a public national injury surveillance system to track fatal and nonfatal firearm injuries. ${ }^{[5]}$ As a result, the burden of fatal and non-fatal firearm-related injuries is unknown.

The 2010 - 2016 Western Cape Injury Mortality Profile reports that firearmrelated homicides doubled between 2010 and 2016, mainly as a result of firearms being used as the main weapon in gangrelated violence. ${ }^{[3]}$ This trend is being observed internationally, as shooting has long been the most common cause of death in homicide cases worldwide, and in 2017 slightly more than half (54\%) of all homicides were carried out with firearms. ${ }^{[7]}$ The 2017 Global Violent Deaths survey supports this, stating that in countries characterised by the highest levels of

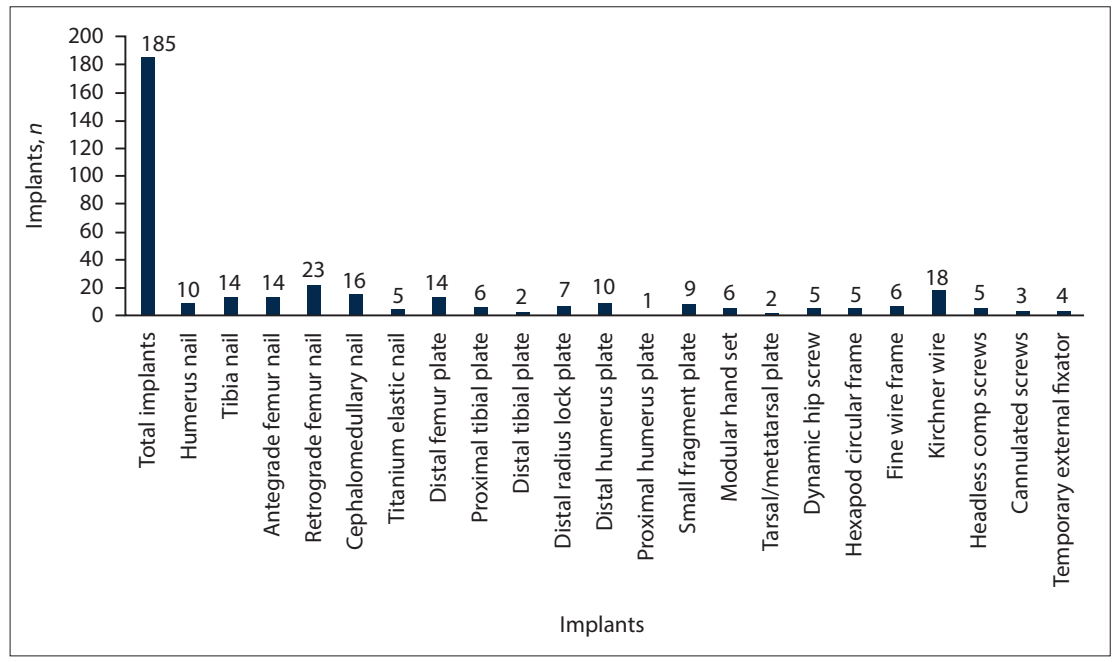

Fig. 3. Orthopaedic implants required.

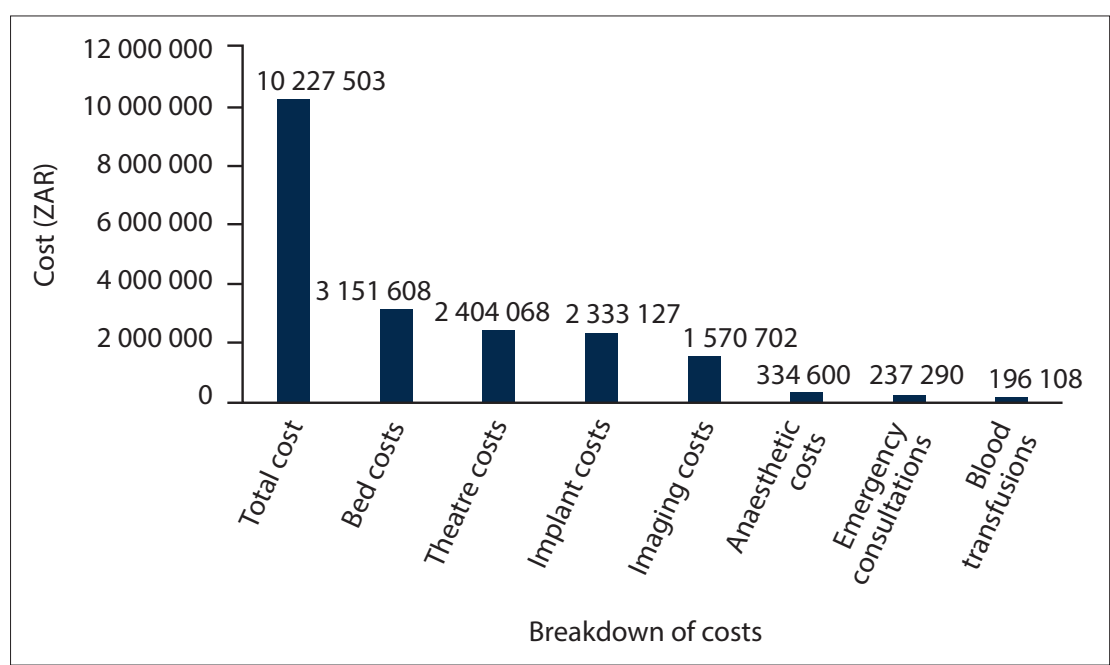

Fig. 4. Total cost breakdown for the study population ( $\mathrm{N}=389$ ).

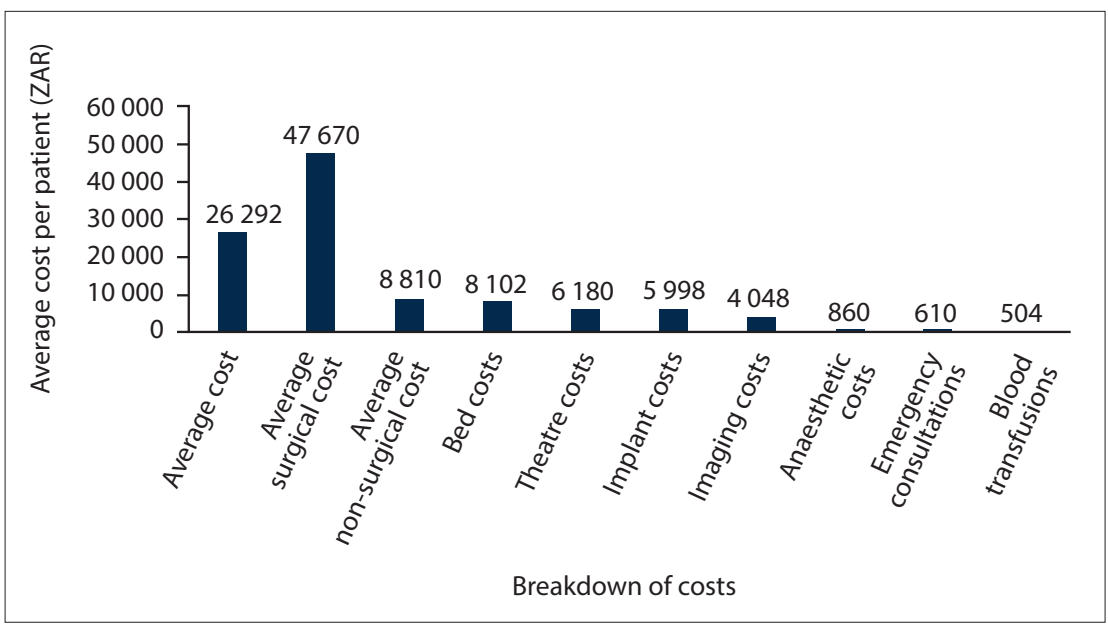

Fig. 5. Average cost per patient for the major expenses associated with managing gunshot relatedorthopaedic trauma.

lethal violence, $\sim 50 \%$ of all killings were committed with a firearm, as opposed to $\sim 12 \%$ in countries with the lowest rates. ${ }^{[9]}$
Matzopoulos et al. ${ }^{[10]}$ assessed the effectiveness of SA's Firearms Control Act 60 of 2000 (FCA), including firearm amnesty 
periods, on firearm homicide rates across five SA cities from 2001 to 2005. They showed a statistically significant decreasing trend in firearm homicides from 2001, with an adjusted year-on-year decrease of $13.6 \%$ per annum. The strength, timing and consistent decline suggest that stricter gun control mediated by the FCA accounted for a significant decrease in homicide overall, and firearm homicide in particular. ${ }^{[10]}$

This downward trend following the FCA implementation continued, resulting in a continuous decline in homicides between 2000 and 2012. ${ }^{[10]}$ A continuous upward trend since 2012 led to a gun amnesty period between December 2019 and May 2020, and by midJanuary 2020, 2266 firearms and 31382 rounds of ammunition had been surrendered to police stations across SA. ${ }^{[1]}$

The above figures do not reflect mortality related specifically to firearm injuries, and the burden of non-fatal firearm-related injuries remains unknown. What is clear is that the overall burden of these injuries is increasing throughout SA, and specifically in the Western Cape, and that firearm-related orthopaedic injuries will continue to burden the healthcare system.

In $2017 / 18$ the SA government spent $13.8 \%$ of the consolidated national budget (projected at ZAR183 billion) on health, with per capita health expenditure of ZAR3 $155 .{ }^{[12]}$ Health budgets and expenditure have become an important aspect of medical decision- and policy-making and need to be considered an integral aspect of providing quality and equal healthcare to all South Africans. Decisions surrounding health budgets and expenditure are particularly pertinent as we prepare for the implementation of National Health Insurance. It is on this background that the present gunshot-related orthopaedic injury cost analysis is based.

SA's public health system lacks a costing culture for individual patients. Hospitals do not perform rigorous cost analysis or itemised billing, and standard cost tables for state health services do not exist. Instead, in the case of Tygerberg Hospital, the hospital allocates pricing for various services provided, including ward admission, radiological imaging and theatre procedures according to the UPFS fee schedule. This schedule is calculated according to the patient's annual income, divided into levels I, II and III. These billing structures were used to calculate the cost incurred during management in the study using a level II patient fee. Orthopaedic implant costs were taken from the 2017 hospital tender document.

The literature supports two different approaches to cost analysis: a bottom-up, microlevel analysis, or a gross top-down assessment. ${ }^{[13]}$ The individually calculated bottom-up analysis is considered more accurate, as it requires detailed summation of costs for all items associated with individual patients. A top-down approach divides institutional costs by the number of patients treated to derive an average cost per patient; this approach is user friendly and does not require detailed records. Previous studies in SA show a degree of variability between these two costing methods. Lutge and Muirhead ${ }^{[14]}$ showed a $20 \%$ variability in unit cost between the two calculation methods when treating orthopaedic trauma patients.

The present study combined use of both the micro and gross approaches. Instances where individual cost could be accurately determined, such as number and type of imaging modality, orthopaedic implants or blood products received, were calculated using a micro-level analysis. Trauma unit, ward and theatre costs were taken from a top-down UPFS billing schedule.

The Tygerberg billing system does not include total theatre time but rather bills according to a procedure code, with long and complex cases being charged accordingly. For this reason, this study did not calculate theatre times. Considering the 180 theatre episodes required in the study, multiplied by the average 3 hours required per gunshot-related orthopaedic case as suggested by Martin et al., ${ }^{\left[{ }^{[5]}\right.}$ in excess of 540 hours ( $>22$ days) of theatre time were used in managing these patients' primary injuries.

The total cost of ZAR10 227503 calculated in this study represents an underestimate of the true costs involved in managing these patients, as it does not include consumables, laboratory studies, medications administered, rehabilitation or patient transport. These parameters are very patient and injury variable and are not well recorded or documented in most cases. Outpatient follow-up and management of complications were also not included in this study, and nor were the indirect cost to society and future loss of productivity, tax revenue and personal earnings due to incapacity.

The mean cost of managing gunshot-related orthopaedic injuries was ZAR26 292 per patient. Patients requiring surgical intervention cost nearly five times the conservative group amount at a mean of ZAR46 670 per patient, compared with a mean of ZAR8 810 in the non-operative group. The significantly increased costs associated with surgical management include theatre cost, expensive orthopaedic implants and longer hospital stays. The findings were compared with Martin et al.'s ${ }^{[5]}$ study, which estimated the burden and average cost of treating GSW victims requiring orthopaedic interventions in 2012. Their average cost was USD2 940 per surgically managed patient; this converts to ZAR41 572 (exchange rate USD1-ZAR14.15 in November 2017). When considering inflation, this figure is comparable to the average cost of ZAR47 670 total cost per surgically managed patient calculated in our study.

The costs involved in treating the average gunshot-related orthopaedic injury patient represent an amount 8 times greater than the annual per capita government health expenditure. Surgically managed patients cost 15 times this amount. This number is comparable to the 13 times per capita expenditure required to manage orthopaedic injuries reported previously. ${ }^{[5]}$

A major benefit of the present study is that it provides an estimate of the costs involved in the non-operative and conservative management of gunshot-related orthopaedic injuries. Considering that the study was performed at a major tertiary hospital, the majority of patients $(n=202 ; 52 \%)$ were still treated conservatively. The true number of non-operatively managed orthopaedic gunshot injuries managed by peripheral health services must contribute a huge number of patients and enormous cost to the gunshot injury epidemic currently being experienced by the healthcare services.

\section{Study limitations}

The major limitation of this study is that it does not include all cost parameters involved in the management of this patient group, as discussed above. It does, however, give a good indication of the cost of the major expenses involved, and we felt that the study's calculated cost provides a representative estimate of the average financial burden of orthopaedic gunshot injuries in SA's public health sector.

\section{Conclusions}

Western Cape health facilities face an extremely high burden of gunshot injuries. The cost of managing the related orthopaedic trauma at one tertiary centre in 2017 was ZAR10 227 503, a mean of ZAR26 292 per patient. Improved understanding of the costs incurred will help the state healthcare system better prioritise orthopaedic trauma funding and training and highlights the urgent need for costsaving measures, specifically primary prevention initiatives. 


\section{Declaration. None.}

Acknowledgements. The authors thank Stellenbosch University and the Department of Orthopaedic Surgery, Tygerberg Hospital.

Author contributions. Conception and design: MvH, NF; data collection: $\mathrm{NlR}, \mathrm{MvH}, \mathrm{SJ}, \mathrm{NF}$; data analysis and interpretation: MvH, NlR; drafting article: $\mathrm{MvH}, \mathrm{NlR}, \mathrm{NF}$; critical revision: all authors; final approval of article: all authors. The article represents independent research and the authors declare that this manuscript is original, has not been published before and is not currently being considered for publication elsewhere. Funding. None.

Conflicts of interest. None.

1. Magruder KM, McLaughlin KA, Elmore Borbon DL. Trauma is a public health issue. Eur J Psychotraumatol 2017;8(1):1375338. https://doi.org/10.1080/20008198.2017.1375338

2. UNODC (United Nations Office on Drugs and Crime). Global Study on Homicide 2013. Vienn UNODC, 2014. https://www.unodc.org/documents/data-and-analysis/statistics/GSH2013/2014 GLOBAL_HOMICIDE_BOOK_web.pdf (accessed 21 January 2020).

3. Western Cape Government: Health. Western Cape Injury Mortality Profile 2010 - 2016. https://www. westerncape.gov.za/assets/departments/health/mortality_profile_2016.pdf (accessed 17 March 2019). 4. Engelmann EW, Maqungo S, Laubscher M, et al. Epidemiology and injury severity of 294 extremity gunshot wounds in ten months: A report from the Cape Town trauma registry. SA Orthop J 2019;18(2):31-36. https://doi.org/10.17159/2309-8309/2019/v18n2a3
5. Martin C, Thiart G, McCollum G, Roche S, Maqungo S. The burden of gunshot injuries on orthopaedic healthcare resources in South Africa. S Afr Med J 2017;107(7):626-630. https://doi.org/10.7196/ SAMJ.2017.v107i7.12257

6. Allard D, Burch VC. The cost of treating serious abdominal firearm-related injuries in South Africa. S Afr Med J 2005;95(8):591-594.

7. UNODC (United Nations Office on Drugs and Crime). Global Study on Homicide 2019. Vienna: UNODC (United Nations Office on Drugs and Crime). Global Study on Homicide 2019. Vienna;
UNODC, 2019. https://www.unodc.org/documents/data-and-analysis/gsh/Booklet1.pdf (accessed 21 January 2020)

8. South African Police Service. Crime statistics: Crime situation in Republic of South Africa twelve (12) months (April to March 2018-19). https://www.saps.gov.za/services/april_to_march2018_19 presentation.pdf (accessed 11 February 2020).

9. McEvoy C, Hideg G. Global Violent Deaths 2017: Time to Decide. Geneva: Small Arms Survey, 2017 https://ethz.ch/content/dam/ethz/special-interest/gess/cis/center-for-securities-studies/resources/docs/ SAS_GlobalViolentDeaths_2017.pdf (accessed 21 January 2020).

10. Matzopoulos RG, Thompson ML, Myers JE. Firearm and non-firearm homicide in 5 South African cities: A retrospective population-based study. Am J Public Health 2014;104(3):455-460. https://doi. org/10.2105/AJPH.2013.310650.

11. Retief C. Amnesty nets thousands of unwanted or illegal firearms. Daily Maverick, 14 January 2020. https://www.dailymaverick.co.za/article/2020-01-14-amnesty-nets-thousands-of-unwanted-or-illegalhttps://www.dailymaverick.co.za/artic

12. UNICEF (United Nations Children's Fund). Health budget South Africa 2017/2018. https://www.unicef. org/esaro/UNICEF_South_Africa_--_2017_--_Health_Budget_Brief.pdf (accessed 21 February 2020).

13. Parkinson F, Kent SJ, Aldous C, Oosthuizen G, Clarke D. The hospital cost of road traffic accidents at a South African regional trauma centre: A micro-costing study. Injury 2014;45(1):342-345. https://doi. org/10.1016/j.injury.2013.04.007

14. Lutge EE, Muirhead D. The epidemiology and cost of trauma to the orthopaedic department at a secondary-level hospital. S Afr J Surg 2005;43(3):74-77.

Accepted 12 May 2020 